\title{
STUDY ON POSSIBLE REPLACEMENT OF THE ALUMINUM SPAR WITH A COMPOSITE STRUCTURE ILLUSTRATED WITH THE CASE OF AGRICULTURAL AIRCRAFT
}

\author{
Mateusz Fałek, Elżbieta Szymczyk, Jerzy Jachimowicz \\ Military University of Technology, Poland
}

\section{INTRODUCTION}

Composite materials are increasingly being used in aviation. Specific stiffness and strength of composite materials (especially CFRP laminate, sandwich structure) are higher compared to metal alloys. They are beneficial features of materials used in aviation. Mass reduction of aircraft structures (e.g. due to the use of composite materials) contributes to an aircraft's better performance in terms of its range, top speed and ceiling and consequently causes an increase in airplanes capacity. Moreover, the use of high-strength and lightweight materials in aviation contributes to longer life time and lower exploitation costs.

The aim of the paper was the study the possibilities of replacing the aluminum spar of an airplane wing with a composite structure. In order to compare the mass and strength of the aluminum with the composite spar, the global shell and local solid models were created and finite elements analysis was performed. The analysis was carried out for the front spar of the wing of the agricultural aircraft PZL-106.

\section{STRUCTURE OF THE WING INCLUDING THE SPAR}

The main parts of an airplane are: wings, fuselage, tail-planes (vertical and horizontal stabilizers), power plant, flight controls and landing gears (Fig. 2.1). The factors that affect an aircraft's performance the most significantly are the outer shape of the plane and the parameters of the engine [1].

The main task of the wings is to produce aerodynamic lift during the flight. The wings also provide suitable controllability and stability of the aircraft. In addition, aircraft engines, armaments, fuel tanks and landing gears can be mounted to the wings [2]. 
PZL-106 Kruk is a low-wing monoplane with a rectangular contour of the airfoil produced in Poland. It is made of a full-metal, semi-monocoque, one- or two- seat structure. The wing is a double-spar construction with integral fuel tanks in the inter-spar space. The wings are joined to the fuselage by fixings at the ends of the spars and V-shaped struts. Figure 2.2 shows the one spar wing of the aircraft $[3,4]$.
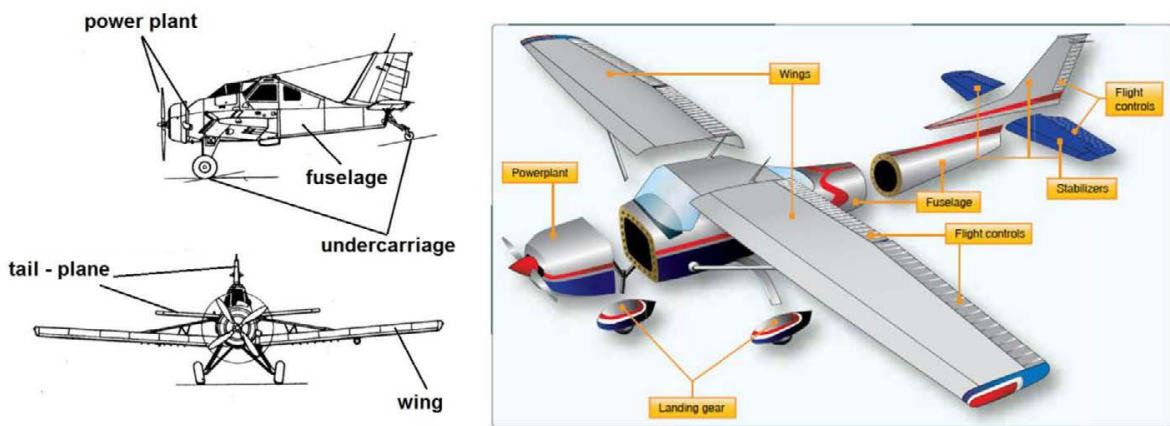

Fig. 2.1. Principal airframe units. Source: own description based on [4, 5]

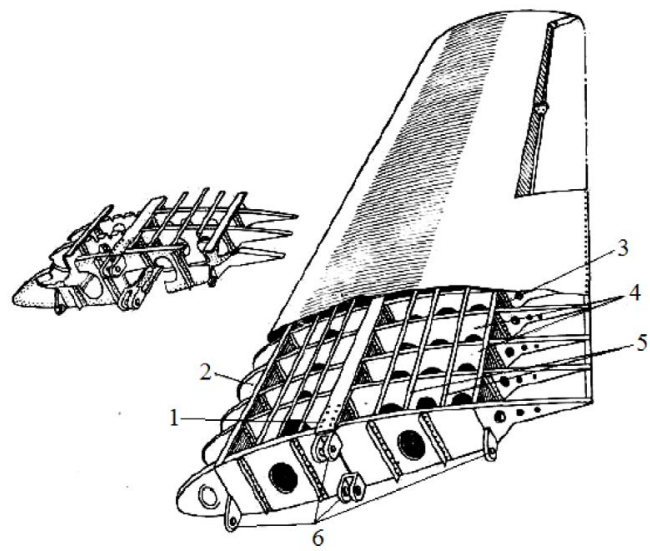

Fig. 2.2. One spar wing of an aircraft: 1 - main spar, 2 -front web, 3 -rear web, 4 -rib, 5-stringer, 6 - fixing/lug of the wing [4]

\section{DETERMINATION OF THE LOAD}

The rectangular (uniform) load distribution was assumed for calculations of both the wing and the spar. Determination of mass forces affecting the wings at Point $\mathrm{A}$ of the maneuvering flight envelope (Fig. 3.1) enables analytical and numerical calculations of the wing load. In the first step, the load ratio was determined at point A of the envelope based on Formula (3.1) [6]. 


$$
n_{A}=2.1+\frac{24000}{W_{l b}+10000}
$$

where:

$\mathrm{W}_{\mathrm{lb}}$ - maximum designing take-off weight in pounds.

$$
\begin{gathered}
\mathrm{W}_{\mathrm{lb}}=\frac{3000}{0.4536}=6622.5[\mathrm{lb}] \\
n_{A}=2,1+\frac{24000}{6622.5+10000}=3.544
\end{gathered}
$$

The value of load ratio at Point A was adopted at the level of 3.6 according to (3.2). The body force at Point A of the load envelope is defined with Formulas (3.3) and (3.4).

where:

$$
Q=n_{A} \cdot W \cdot g[N]
$$

$\mathrm{g}=10 \mathrm{~m} / \mathrm{s}^{2}-$ Earth acceleration.

$\mathrm{W}$ - maximum designing take-off weight in Newtons.

$$
\mathrm{Q}=3.6 \cdot 3000 \cdot 10=108000[\mathrm{~N}]
$$

About half the determined body force is load carried by one wing (excluding lift force on the tail-planes). The average load distributed along one wing was determined according to Formula (3.5).

where:

$$
q_{l}=\frac{0.5 \cdot Q}{l}\left[\frac{N}{m m}\right]
$$

$l=6530 \mathrm{~mm}-$ wing length

$$
q_{l}=\frac{0.5 \cdot 108000}{6530}=8.27\left[\frac{\mathrm{N}}{\mathrm{mm}}\right]
$$

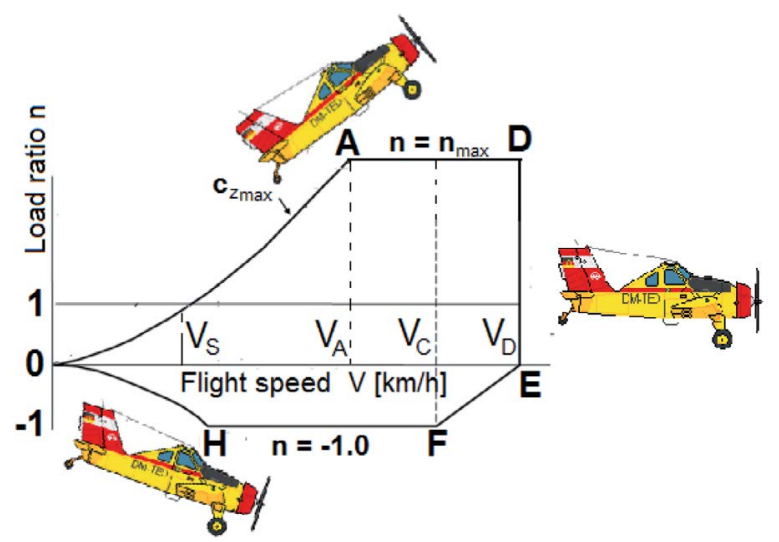

Fig. 3.1. Exemplary maneuvering flight envelope of aircraft in symmetrical flights [7] 
The load carried by one spar was estimated based on the maximum deflection of the wing. It was assumed that the deflection of the wing components (spars and covering) was the same as in the case of the whole wing. After the analysis of the beam model of the wing subjected to load $\mathrm{q}_{l}=8.27 \mathrm{~N} / \mathrm{mm}$, a maximum deflection equal to $181 \mathrm{~mm}$ was obtained. The spar geometry (webs, lower and upper caps as well as vertical stiffeners) was described in detail in the shell model. Based on the spar shell model the value of the distributed load was iteratively determined. Good agreement of the deflection in the beam model of the wing and the shell model of the spar was obtained for load $q=1.25 \mathrm{~N} / \mathrm{mm}$ (applied to the shell model).

In order to perform a more detailed analysis, the following models were created:

- a beam model of the wing to determine the deflation of the structure;

- shell models of the main spar to determine the value of the distributed load carried by the main spar and to perform comparison analysis of spar deflection for aluminum and composite structures;

- solid models of a part of the main spar to perform local stress analysis and failure analysis in the lug region for aluminum alloy and composite structure, respectively.

The models were created in the system units: $\mathrm{N}, \mathrm{mm}, \mathrm{s}$.

\section{MATERIALS USED IN ANALYSIS}

The PZL-106 aircraft spar was made of 2024T3 aluminum alloy. The main alloy addition of 2024T3 is copper. The material is characterized by high specific strength and good fatigue performance. The basic mechanical properties of 2024T3 aluminum alloy are shown in Table 4.1.

Table 4.1. Properties of 2024T3 aluminum alloy [7]

\begin{tabular}{|c|c|}
\hline & Stop 2024T3 \\
\hline$E$ & $70000 \mathrm{MPa}$ \\
\hline$v$ & 0.3 \\
\hline $\mathrm{R} 0,2$ & $334 \mathrm{MPa}$ \\
\hline $\mathrm{Rm}$ & $465 \mathrm{MPa}$ \\
\hline$\rho$ & $2780 \mathrm{~kg} / \mathrm{m} 3$ \\
\hline
\end{tabular}

In this paper, the possibility of replacement of the aluminum spar with a CFRP (carbon fiber reinforced polymer) composite structure is analyzed. The properties of CFRP lamina are shown in Table 4.2. The composite material is made from minimum two different components. The connection of the components 
is at the macroscopic level. Most composites are made from two phases - the continuous one called the matrix and dispersed one named the reinforcement. The properties of the composite depend on the properties of the component phases, the method of the distribution of the reinforcement in the matrix, the reinforcement volume ratio and the geometrical features of the reinforcement. Generally, the properties of composite material are better than or different from the properties of the components from which it is made [9]. CFRP laminate is a polymeric material reinforced with carbon fibre. The CFRP matrix is epoxy resin. CFRP laminate is one of the most durable and relatively light constructional materials. Moreover, it is stable to heat and it has high specific stiffness and strength. The disadvantage of CFRP material is brittleness and higher cost in relation to metal alloys [10].

Table 4.2. Properties of CFRP laminate [11]

\begin{tabular}{|c|c|c|c|c|c|}
\hline Young's modulus 1 [GPa] & $\mathrm{E}_{1}$ & 143 & Tensile strength 1 [MPa] & $\mathrm{S}_{1 \mathrm{t}}$ & 2072 \\
\hline Young's modulus 2 [GPa] & $\mathrm{E}_{2}$ & 10 & Compressive strength 1 [MPa] & $\mathrm{S}_{1 \mathrm{c}}$ & 1450 \\
\hline Young's modulus 3 [GPa] & $\mathrm{E}_{3}$ & 10 & Tensile strength [MPa] & $\mathrm{S}_{2 \mathrm{t}}$ & 46 \\
\hline Poisson ratio 1-2 & $\mathrm{v}_{12}$ & 0.29 & Compressive strength 2 [MPa] & $\mathrm{S}_{2 \mathrm{c}}$ & 200 \\
\hline Poisson ratio 1-3 & $\mathrm{v}_{13}$ & 0.29 & Tensile strength 3 [MPa] & $\mathrm{S}_{3 \mathrm{t}}$ & 46 \\
\hline Poisson ratio 2-3 & $\mathrm{v}_{23}$ & 0.5 & Compressive strength 3 [MPa] & $\mathrm{S}_{3 \mathrm{c}}$ & 200 \\
\hline Shear modulus 1-2 [MPa] & $\mathrm{G}_{12}$ & 5200 & Shear strength 1-2 $[\mathrm{MPa}]$ & $\mathrm{S}_{12}$ & 105 \\
\hline Shear modulus 1-3 $[\mathrm{MPa}]$ & $\mathrm{G}_{13}$ & 5200 & Shear strength 1-3 $[\mathrm{MPa}]$ & $\mathrm{S}_{13}$ & 105 \\
\hline Shear modulus 2-3 $[\mathrm{MPa}]$ & $\mathrm{G}_{23}$ & 3200 & Shear strength 2-3 $[\mathrm{MPa}]$ & $\mathrm{S}_{23}$ & 41 \\
\hline Density $\left[\mathrm{kg} / \mathrm{m}^{3}\right]$ & & & & $\rho$ & 1770 \\
\hline
\end{tabular}

One important parameter that should be taken into account when designing a composite spar that can replace the metal structure is its stiffness. The use of the composite material should not affect or change the performance (i.e. stiffness and deflection) of the PZL-106 wing. The arrangement of the CFRP laminate layers was selected in such a way as to create the quasi-isotropic material with tensile and compressive stiffness similar to that of 2024T3 aluminum alloy. According to literature [11], it was assumed that thickness of a single CFRP lamina is about $0.133 \mathrm{~mm}$. Laminate arrangements for each spar component are listed in Table 4.3. It was assumed that all the laminates used on the composite spar are symmetrical. After defining the composite material in the MSC Patran system ("Materials Composite" card) $\mathrm{E}_{11}$ stiffness was read (in the "Composite Material Properties" card). This stiffness is calculated according to the classical theory of lamination. 
Table 4.3. Comparison of thickness and laminate arrangement for each component

\begin{tabular}{|c|c|c|c|c|}
\hline & Spar web & lower cap & upper cap & stiffeners \\
\hline $\begin{array}{c}\text { Original thickness of the } \\
\text { aluminium component } \\
{[\mathrm{mm}]}\end{array}$ & 2 & 3 & 2 & 2 \\
\hline $\begin{array}{c}\text { Thickness of the composite } \\
\text { component }[\mathrm{mm}]\end{array}$ & 1,995 & 3,059 & 1,995 & 1,995 \\
\hline Arrangement of laminate & $\mathrm{p} 1$ & $23 \mathrm{x} 0.13$ & $20 \mathrm{x} 0.13$ & $20 \mathrm{x} 0.13$ \\
\hline $\mathrm{E}_{11}[\mathrm{MPa}]$ & 71206 & $\mathrm{p} 2$ & $\mathrm{p} 1$ & $\mathrm{p} 1$ \\
\hline
\end{tabular}

p1: $\left[0 / 45 / 90_{2} /-45 / 0_{2} / 90 / 0_{2} /-45 / 90 / 45 / 0\right]_{\mathrm{S}}$

p2: $\left[0 / 45_{2} / 90 / 0 / 90_{2} /-45_{2} / 0_{3} /-45_{2} / 90_{2} / 0 / 90 / 45_{2} / 0_{2}\right]_{S}$

\section{FEM ANALYSIS OF THE SPAR}

\subsection{Shell models}

In the first step, the shell model was analysed. The model was discretized for 27093 thin shell Quad4 elements with an average side length of $10 \mathrm{~mm}$ (Fig. 5.1). Vertical stiffeners were discretized for 31 Bar2 elements (each) with a T-cross section (symmetrically located on both sides of the spar) and an average length of $9.7 \mathrm{~mm}$. The V-shaped strut was simplified and modelled by a single rod element.

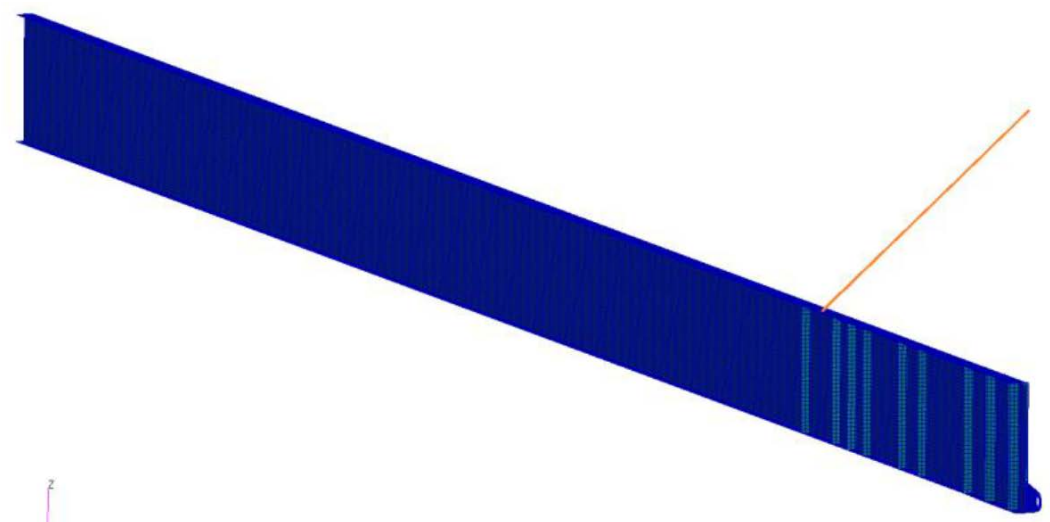

Fig. 5.1. Symmetrical shell model of the spar 
The strut was connected to the spar using the MPC RBE2 option (Fig 5.2). The independent node belonging to the strut was connected to the nearest (dependent) 28 nodes located on the spar. Using this option, displacements in $\mathrm{X}, \mathrm{Y}$ and $\mathrm{Z}$ directions are transmitted. In the shell model of the spar, the displacement in $\mathrm{X}, \mathrm{Y}$ and $\mathrm{Z}$ directions were fixed at the end of the strut and in the fixing/lug hole (Fig. 5.3). A translational $X$ degree of freedom (perpendicular to the spar surface) was fixed at the nodes corresponding to the transverse ribs location. The uniformly distributed load $\mathrm{q}$ was applied to the upper and lower cap (along the centre line on the entire length of the spar). Static analyses were carried out with Marc code [12].

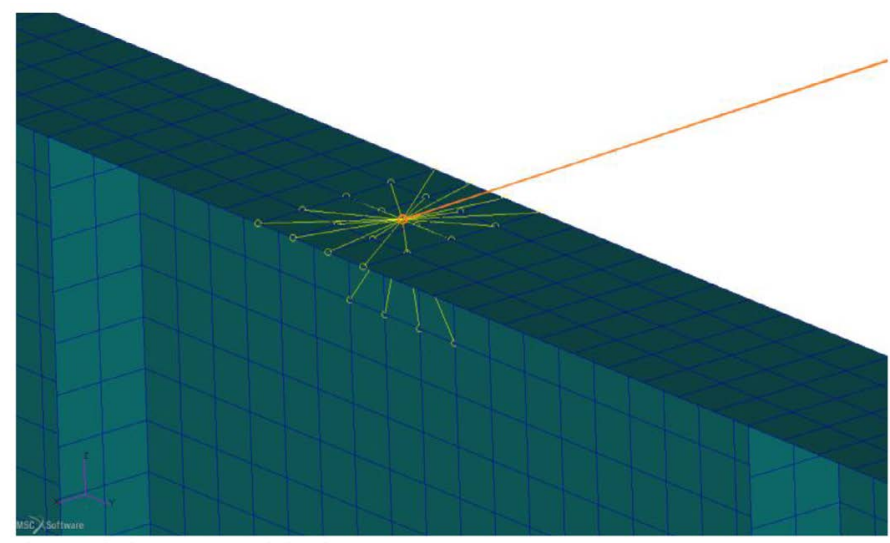

Fig. 5.2. Connection of the spar with the strut (MPC RBE2)
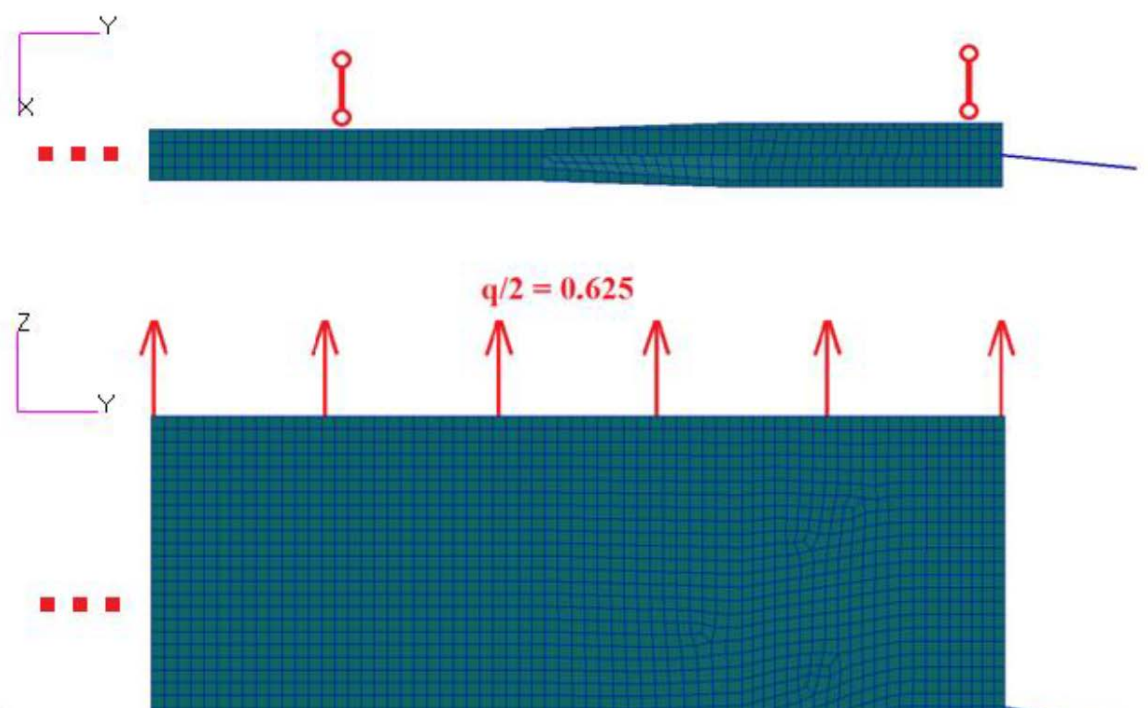

Fig. 5.3. Load and boundary conditions in the shell model of spar 
In order to simplify comparison of the shell models of aluminum and composite spars, they are called Alu_Shell Model and Comp_Shell Model, respectively. The Alu_Shell Model was made of isotropic material -2024T3 aluminum alloy (with properties shown in Table 4.1). The Comp_Shell Model was made of a composite spar (components were defined according to Tables 4.2 and 4.3) and aluminum alloy wing lug. Displacements of shell models, comparison of the composite and the aluminum spar, are presented in Fig. 5.4.

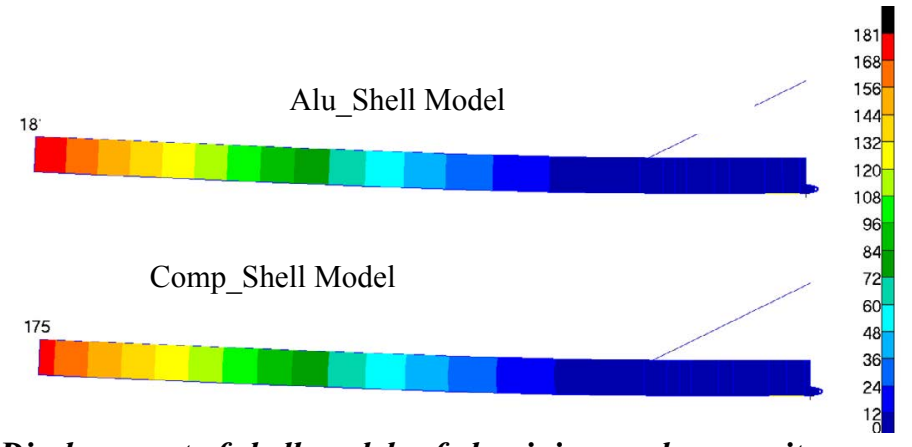

Fig. 5.4. Displacement of shell models of aluminium and composite spars [mm]

The density of the CFRP lamina $\left(\rho_{\mathrm{L}}=1770 \mathrm{~kg} / \mathrm{m}^{3}\right)$ is $36 \%$ lower compared to the aluminum alloy $\left(\rho_{\mathrm{A}}=2780 \mathrm{~kg} / \mathrm{m}^{3}\right)$. The replacement of the aluminum alloy spar with the composite structure results in reduction of its total mass. Total mass of the spar made of 2024T4 aluminum alloy and CFRP laminate are compared in Table 5.1

Table 5.1. Mass of the spar made of 2024T3 aluminum alloy and CFRP laminate

\begin{tabular}{|c|c|c|}
\hline & Mass $[\mathrm{kg}]$ & Mass index \\
\hline Aluminium spar & 16 & 1.0 \\
\hline Composite spar & 10.2 & 0.64 \\
\hline
\end{tabular}

\subsection{Solid models}

Next, the solid models of the spar part close to the lug were analysed. The solid model was discretized to 136956 Hex 8 solid elements with an average side length of $2 \mathrm{~mm}$ (Fig. 5.5). Figure 5.6 shows the mesh of a solid model in the area of lug region. In the solid model of the spar part, boundary conditions were applied similarly to the shell model. Three translational degrees of freedom were fixed for the nodes located on the surface of the lug hole. Additionally, displacements obtained from the analysis of the shell model were used to define the boundary conditions on the cut surface of the analysed part of the spar (Fig 5.5). A translational degree of freedom $X$ (perpendicular to the spar surface) 
was fixed to describe the influence of transverse ribs as in the shell model. The upper and lower spar caps are subjected to pressure related to the uniformly distributed load $\mathrm{q} / 2$. The boundary and load conditions are shown in Figure 5.7.

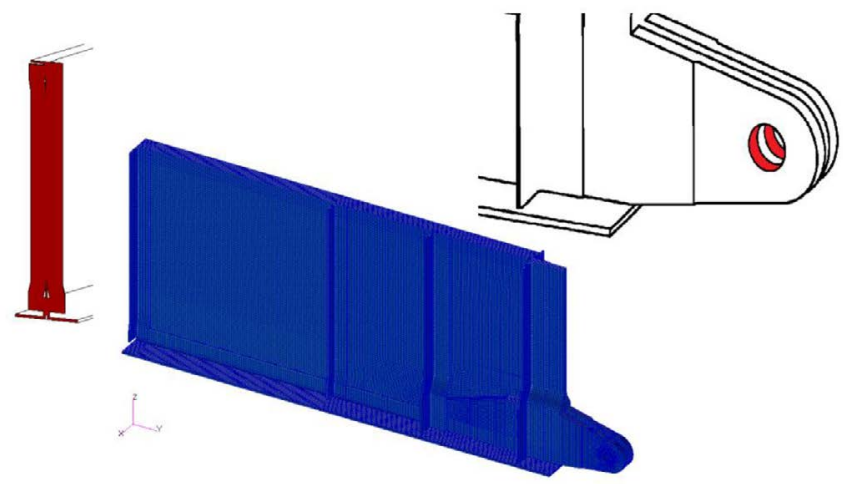

Fig. 5.5. Solid model. Fixed and subjected to kinematic load surfaces are shown in red

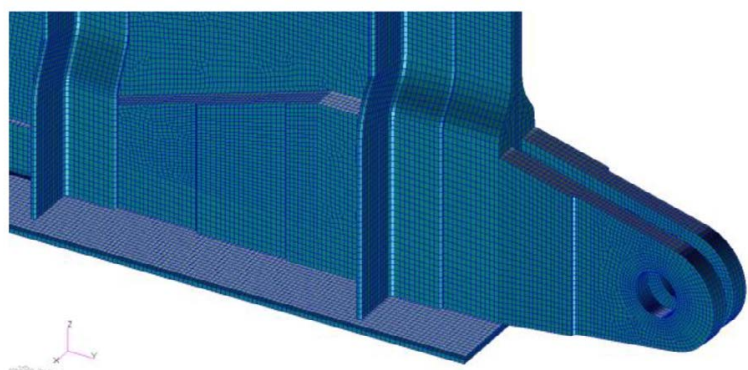

Fig. 5.6. Mesh in the anchorage/lug region
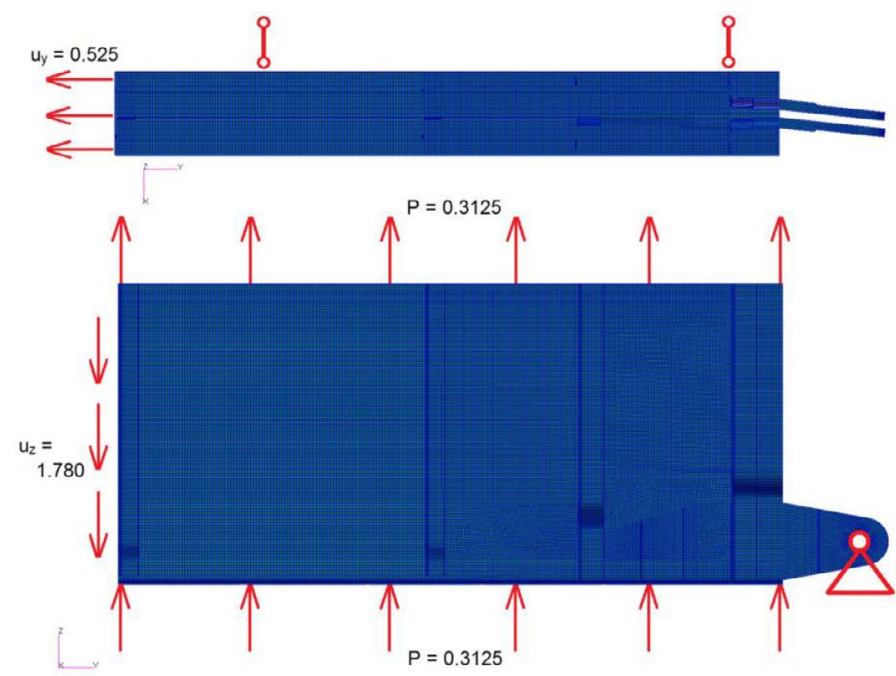

Fig. 5.7. Boundary conditions in the solid model 
Two solid models of the spar were analyzed. The first model (named/called Model Alu_Solid) was made of the isotropic material - 2024T3aluminium alloy. In the second model, called Model Comp_Solid, the composite material with plies arranged according to Table 4.3 was used for the spar components while the aluminum alloy was used for the lug. The spar geometry in the anchorage/ lug region was modified to reduce stresses and failure indices and to achieve well designed metal - CFRP laminate connection.

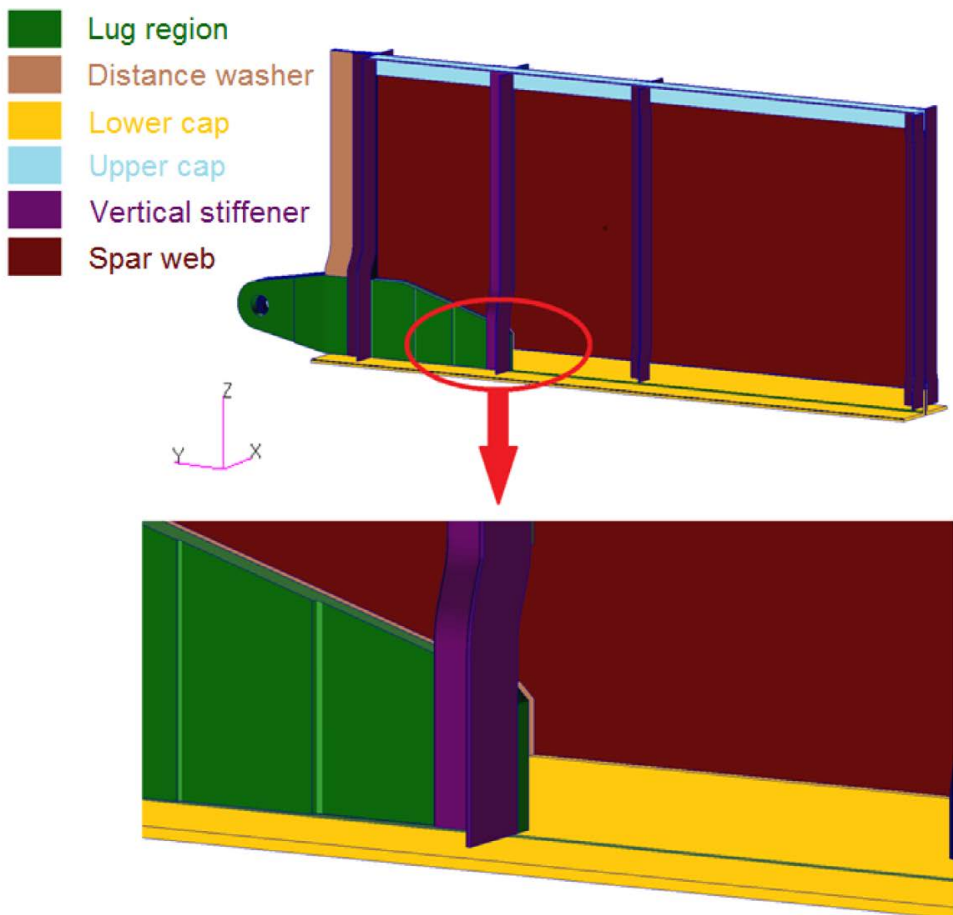

Fig. 5.8. The original model of the spar in the lug region, place of geometry modification is marked

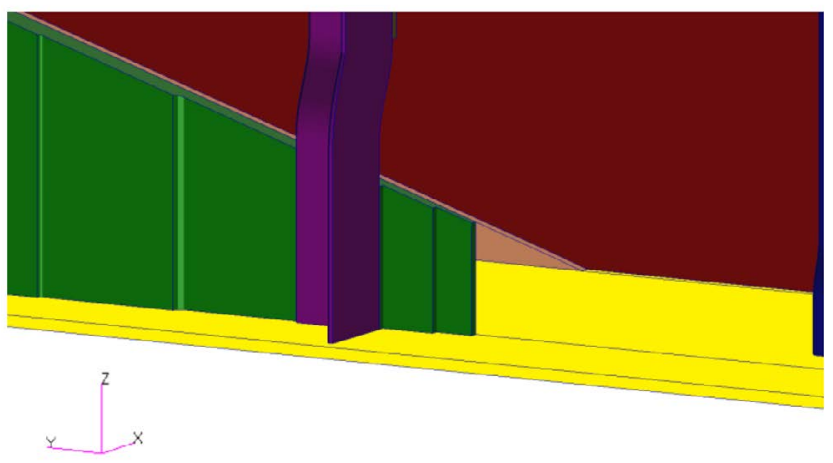

Fig. 5.9. Modified geometry of the lug region 
Figure 5.8 shows the original geometry of the spar based on the engineering drawing of PZL-106 wing. The modification of the spar geometry (Fig. 5.9), which included enlarging of the lug region, and gradual decreasing in the thickness of laminate layers, constitutes a smooth transition region from one component to the other and reduces unwanted stress concentrations (reduces the geometrical notch). The lug region was extended by $60.5 \mathrm{~mm}$ and connected to the lower cap. The thickness of this component was gradually decreased every $2 \mathrm{~mm}$.

The CFRP laminate with the arrangement $\left[00_{2} / 45_{2} / 90_{2} /-45_{2} / 0_{3} /-45_{2} / 90_{2} / 45_{2} / 0_{2}\right]$ ${ }_{\mathrm{S}}$ was used in the lug region. Young's modulus of this laminate $\mathrm{E}_{11}=69112 \mathrm{MPa}$ is comparable to the modulus of aluminum alloy. In the lug region, the material was gradually changed from the aluminum alloy close to the fitting hole to the CFRP laminate at the other end of this region [13]. The arrangement of the aluminum-CFRP laminate connection is shown in Figure 5.10.

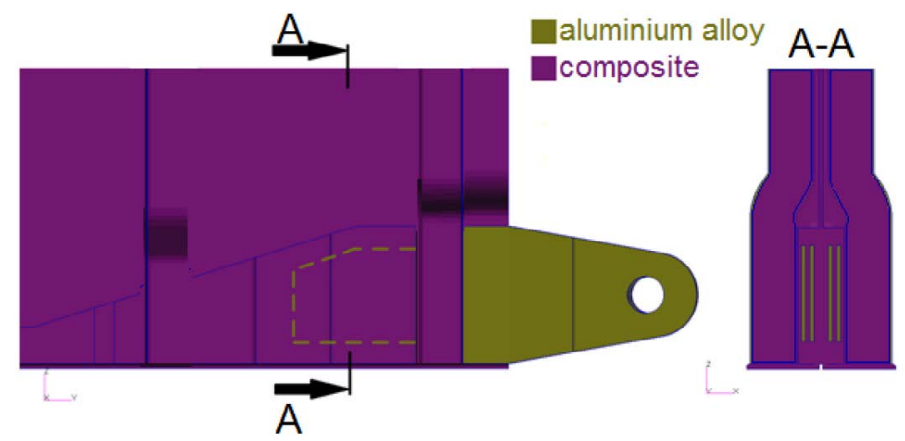

Fig. 5.10. Configuration of aluminum-CFRP laminate (FML) in the lug region

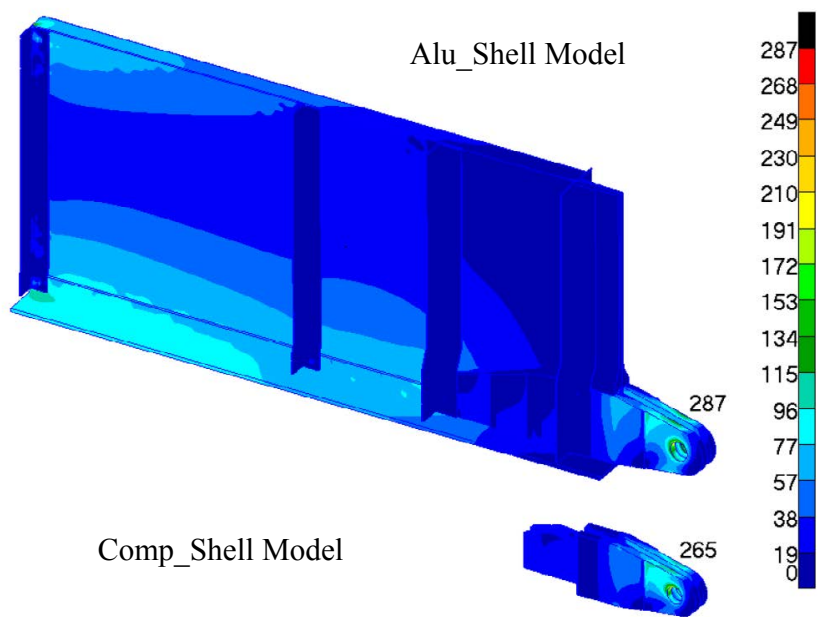

Fig. 5.11. Comparison of HMH stress states in [MPa] for solid models made of aluminum alloy and composite 
An equivalent $\mathrm{HMH}$ stress state in the original aluminum spar model is presented in Fig. 5.11 and compared with the stress state in the aluminum part of the composite spar (close to the lug hole). Stress states (component $\mathrm{Y}$ along the spar) and failure indices according to the Hashin criterion for composite spar model with the original geometry are shown in Fig. 5.12 and 5.13, respectively.

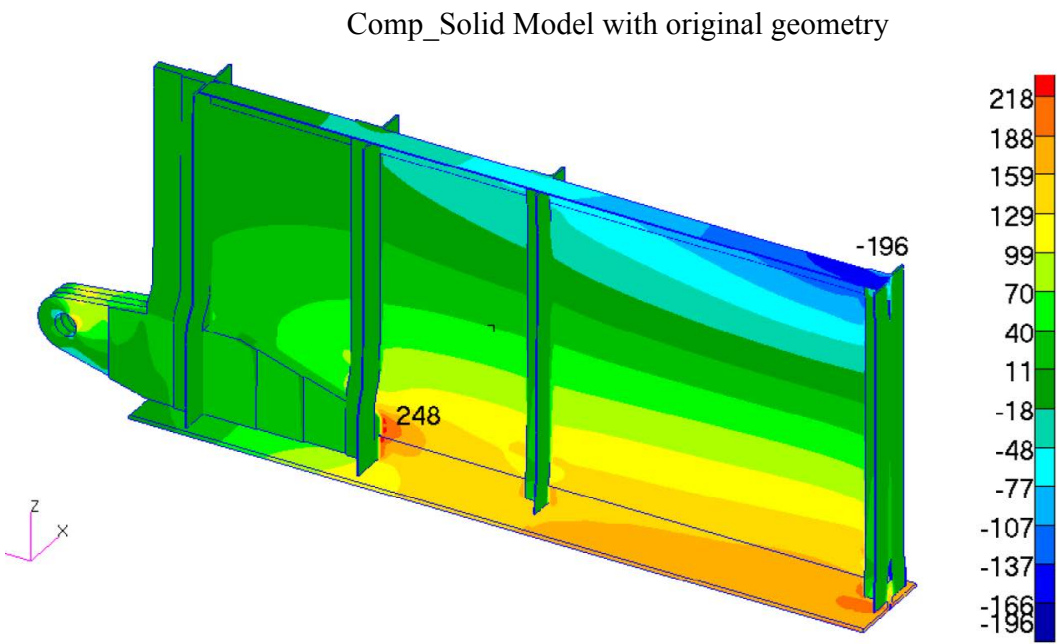

Fig. 5.12. Stress state - component Y along the spar in [MPa] for the composite solid model with the original geometry

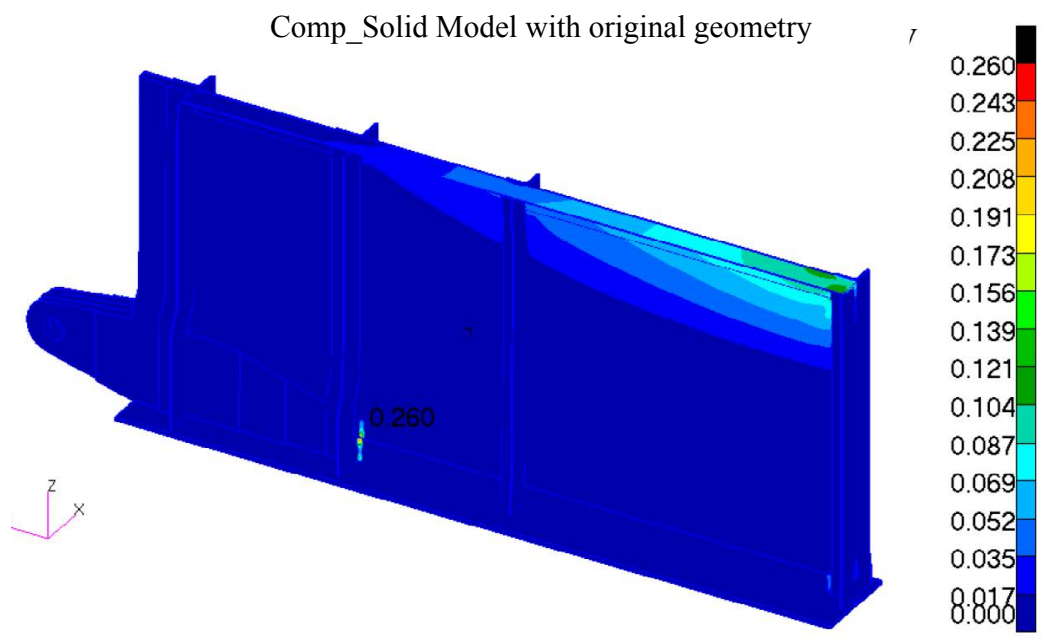

Fig. 5.13. Maximum failure index state according to the Hashin criterion for the composite solid model with the original geometry 
Stress states (component $\mathrm{Y}$ along the spar) and failure indices according to the Hashin criterion for the composite spar model with the modified geometry are shown in Fig. 5.14 and 5.15, respectively.

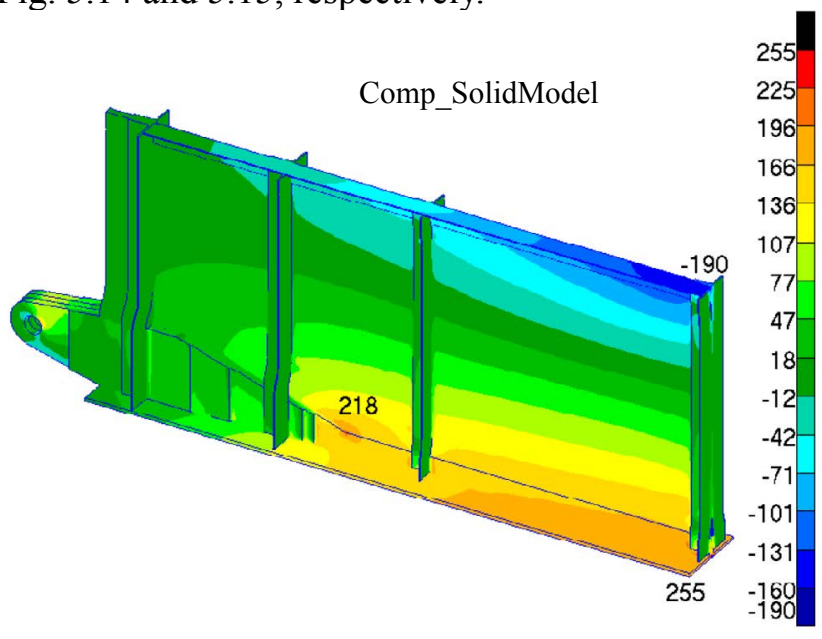

Fig. 5.14. Stress state - component Y along the spar in [MPa] for the composite solid model with the modified geometry in the lug region
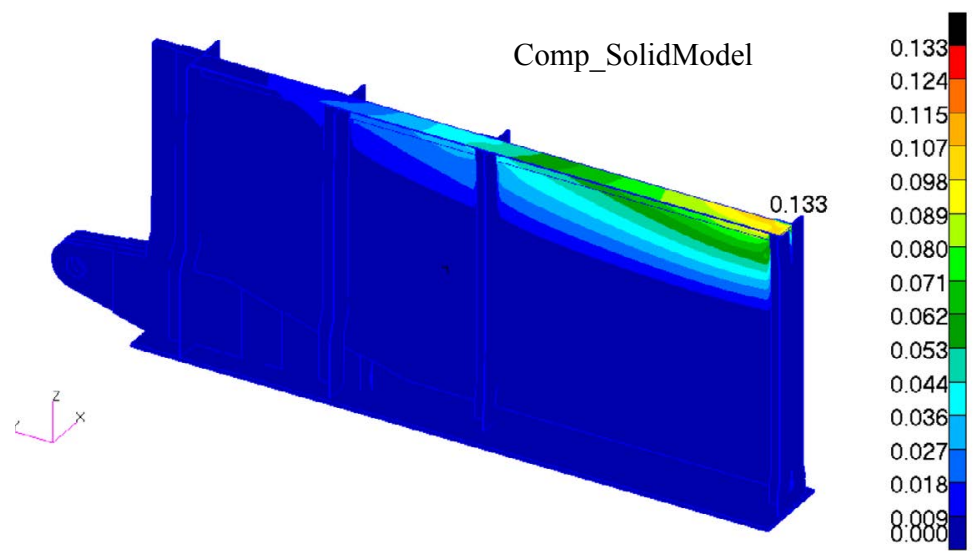

Fig. 5.15. Maximum failure index state according to the Hashin criterion for the composite solid model with the modified geometry in the lug region 
The maximum HMH stress in the aluminum alloy spar is $287 \mathrm{MPa}$ and it is located close to the fitting hole (Fig 5.11). In the composite spar, the HMH stress state was analyzed only in the aluminum part of the structure. Using the composite material results in stress reduction in the lug region (close to the fitting hole) to the value of $265 \mathrm{MPa}$ (decrease by 7,7\%). The stress state in Y direction along the spar after modification in the lug region is shown in Fig. 5.14. The maximum tensile stress of $255 \mathrm{MPa}$ occurs in the lower cap, while the compressive stress of $190 \mathrm{MPa}$ is obtained in the upper cap. The modification of the spar geometry cause the reduction of tensile stresses in the modified lug region. HMH stresses are not a good measure for assessing the strength of composite structures. In the composite structure, the Hashin indices were analysed. The maximum index according to the Hashin criterion reached the value of 0.133 . This index concerns compression of fibres.

\section{SUMMARY AND CONCLUSIONS}

The aim of the paper was to analyze the possibility of replacing an aluminum alloy spar with a composite structure. In the paper, the structure of the agricultural PZL 106 aircraft, especially the wing front spar, and the advantages of using composite materials were presented. Four spar models (two shell and two solid models) were created and FEM analyses were carried out. The following assumptions were made with reference to the composite structure:

- a lug region should be made of aluminum alloy as in the original structure;

- the spar components (webs, caps and stiffeners) should be made of the quasi - isotropic CFRP laminate;

- the stiffness of the laminate should be similar to the stiffness of the aluminum alloy.

Based on the analytical calculations and numerical analyses, the mass and the strength of aluminum and composite structures were compared. The geometry of the lug region was modified. As a result of replacing the aluminum alloy spar with the composite structure and the local modification of its geometry in the lug region, it was found that:

- maximum HMH stress close to the fitting hole decreased from 287 to 265 $\mathrm{MPa}$ (from $86 \%$ to $79 \%$ of yield stress of $2024 \mathrm{~T} 3$ aluminum alloy),

- maximum Hashin index for the composite structure was 0.266 (including safety factor 2). This index refers to the compression of the fibres and is obtained in the upper cap far from the lug region,

- the use of composite materials contributes to increasing the strength of the spar and also reducing the mass of the structure by $36 \%$. 


\section{REFERENCES}

[1] Cichosz E. (1968). Konstrukcja i praca płatowca, Warszawa: WAT.

[2] Olejnik A. (1984). Konstrukcja samolotów Część II, Konstrukcja i praca płatowca, Warszawa: WAT.

[3] www.polot.net/

[4] Dokumentacja skrzydła PZL Kruk 106, www.samolotypolskie.pl/samoloty/2330/126/ PZL-106-Kruk.

[5] Aviation Maintenance Technician Handbook - Airframe, vol. 1. FAA. 2012, www. faa.gov

[6] Praca Zbiorowa (1994). Wspólne przepisy lotnicze JAR - 23, Bruksela.

[7] Jachimowicz J., Szymczyk. E., Łukasiński. Ł., Puchała. K. (2015a), Modelowanie wytrzymałościowe $i$ analiza masowo materiatowa dźwigara skrzydla samolotu rolniczego, Logistyka, 4, nr. 2, s. 3726-3733.

[8] Podgórski J. (2010), Metoda elementów skończonych-wprowadzenie, Lublin.

[9] encyklopedia.pwn.pl/haslo/;3971691

[10] Oczoś K., (2008). Kompozyty włókniste - właściwości, zastosowanie, obróbka ubytkowa, Mechanik, 7, s. 579-592.

[11] Jachimowicz J., Szymczyk E., Puchała K. (2015), Study of material mass efficiency and numerical analysis of modified CFRP laminate in bearing conditions, Composite Structures, 134, 114-123, doi 10.1016/j.compstruct.2015.08.031

[12] MSC.Marc (2011). Theory and user information. Santa Ana MSC Corp.

[13] Niu M. (1992), Composite airframe structures, Hong Kong: Conmilit Press Ltd. 